\title{
The Phenomenon of the Corona-virus Crisis in the Essays of Students of Leisure Education at the Faculty of Theology of the University of South Bohemia in České Budějovice Stanislav Suda
}

DOI: $10.32725 /$ cetv.2021.015

\begin{abstract}
:
The topic of the corona-virus crisis is current and data on the ways in which individual students experience this crisis and the impact on their studies or profession are not yet known. The conducted qualitative survey is therefore devoted to experiencing this crisis from the perspective of students and the importance of the foundations of their attitudes in coping with this challenging situation. Students of the bachelor's programme Leisure Education were given an assignment - an authorial essay on the topic 'I, my profession, and covid'. This was then phenomenologically analysed in order to determine the subjective level of experiencing the crisis. From a sample of 182 essays, seven more general attitude codes were read. They illustrate students' experiences and the way of coping with this phenomenon (using one's personal attitude) and show the advantage of certain attitude codes (personal settings) for coping with a long-term crisis. The implications of the results are possible at two levels: they offer a methodological opportunity in comparative studies with the expected concurrent (methodologically differently constructed) studies of the corona-virus crisis and also point to the need for an active personal setting in a long-term crisis.
\end{abstract}

Keywords: essays, corona-virus crisis, qualitative methodology, attitudes, covid-19

\section{Introduction}

When thinking about the method of data acquisition, we decided to use the potential of students whom we accompany during the studies, namely within the methodological specialisation of personal and social education in the bachelor's programme Leisure Education. The question 'I, my profession, and covid' was aimed at one's own experience of the phenomenon of the corona-virus crisis. It was stated in the clarifying instruction that these are their own considerations in any form and length, and that they are not subject to any evaluation. Subsequently, this question was 
evaluated by a phenomenological analysis of the essays. ${ }^{1}$ A qualitative approach was then used to quantify students' attitudes to the crisis. We see the essence of the survey in understanding the student's attitude towards the new situation, in clarification of the individual thought process which takes place due to the broader social context in terms of value or ethics. In terms of research focus and the outlined methodological and philosophical approach, it will be more advantageous to talk about the meaning of the research than about the goals of research. ${ }^{2}$

\section{On the Methodology}

The sample thus consists of 182 submitted essays written by students of the course on free-time pedagogy who have been in contact with us, as teachers, for at least one semester and have submitted at least two or more essays in the format of open forms. What is meant by this? Students have repeatedly experienced the fact that the submitted authorial essay is not the subject of evaluation. The submitted authorial work is provided in order to receive feedback from other students only. From the position of a teacher, it is evaluated only on a scale with two items: submitted (the student met the requirements) or not submitted (the student did not meet requirements). This may, on the one hand, lead to content uncertainty, but on the other hand, this statement speaks about the writer's position more clearly. The aim of such a collection of research data is to obtain evidence of the inner experience of specific individual participants. In this way the statements can capture the phenomenon being studied authentically. Often it can be an unprofessional, naive, metaphorical testimony, with a personal or artistic overlap. However, from this partnership-like research perspective 'with people', any authentic statement seems to be very valuable and it is inappropriate to evaluate it in any way, with regard to future pedagogical activities. Participants would then become objects of research 'on people' or, at least, 'about people.'

At present, the vast majority of quantitative data collection is based on anonymous data collection. Research uses electronic templates in the Internet environment, on social networks, or directly using databases of students and staff. The purpose is to collect the largest possible sample of respondents who answer the questions. In standard reflection upon the way how to obtain quantifying data, we would focus on the subject of research and set goals regarding the research sample and research hypotheses. We know from our own experience that, due to the frequency of such questionnaire surveys, the motivation of respondents to participate in the survey and their real interest in questions and honest answers is gradually decreasing. We believe that the alternative is to return to a more personal way of investigating and to start with the questions that run through the minds of the respondents themselves.

\section{Attitude as a Key to Research into the Phenomenon}

Indeed, we believe that the outbreak of the virus and the impact on the entire population through government measures is a society-wide fact - a phenomenon. The problem is that the study and research into phenomena is currently downplayed. Let us recall the methodological assumptions. In the methodological aspect we can start from the assumptions of constructivist theory which is summarised by František Jiránek in several points. He says that relationships really exist, the

Cf. Tomáš ŘIHÁČEK, Ivo ČERMÁK, Roman HYTYCH et al., Kvalitativní analýza textů: čtyři př́stupy, Brno: Masarykova univerzita, 2013. 
individual reveals them by his activity, and this activity develops from material activity into thought activity in connection with the development of abstraction, that is, the ability to take positions on the world which are conditioned more and more socially. Considering working with language, this specifically means that the meaning of the word cannot be shared by pointing at the designate. The individual must work towards it through his own activities and cooperation with others, especially with adults. ${ }^{4}$ In connection with the study of the phenomenon of play, Jiři Černý points out the fact that, in general, we should not focus on what the phenomenon is, but on how this phenomenon is with us. ${ }^{5}$ This creates a paradox of a qualitative view of the research into phenomena.

Specifically, the corona-virus crisis is not research into the 'subject' of the corona-virus crisis. We do not explore the questions like what is a virus, what is a crisis, what will be the impact, which measures work medically, hygienically. The optics of research are shifting towards the subject who is experiencing corona-crisis and is giving his testimony. The subject is an active factor in the synthesis of unexpected experiences evoked by the current situation and in the formulation of his own attitude to the situation. The prerequisite for the research is therefore the discovery of certain attitude codes in essays that tell us how specific individuals respond to this society-wide phenomenon. We therefore considered the basic research question over a long period of time and finally chose the open option of the written assignment on the topic: Me, my profession, and covid. The instructions again emphasised the essay as an open form. There was the possibility of grasping the topic in any way. The essay is not subject to any evaluation of the text. The requirement was the submission of a text only. The text will not be evaluated in terms of content, literary character, spelling, or grammar. It was worthwhile to take this risk again, as with other texts within personal social education. With few exceptions, the texts ranged from one to three standard pages.

As mentioned above, it was necessary to read all the essays carefully first and to clarify the meaning of formulations by asking questions during the colloquia. If compared to the classic questionnaire survey, the whole process is extremely time consuming due to the size of the sample. However, we believe that, thanks to the use of a qualitative method, this provides a more authentic insight into the issue of personal experience. For these reasons, the widely quoted passages of the essays are longer, as they need to illustrate the ways in which the author's statement is formed - we also see the advantage of using a qualitative methodology in this. ${ }^{6}$ We also believe that the discovered codes tell far more about the internal situation of the participants than the refuted or confirmed hypotheses obtained from the answers to the researcher's questions in the questionnaire survey. From the mentioned sample of 182 essays (submitted by students of the bachelor's programme Leisure Education), seven with a more general attitude were removed, which illustrate the students' experience during the second wave of the corona-virus crisis.

\section{It Is Just Like That}

This type of attitude is defined by a certain formality or disinterest. Students extensively describe the current state, including realities from everyday life. The interesting thing here is a kind of alienation and falling into a stereotype.

So I wonder if covid has influenced my life. Since I was mostly at home, it basically missed me. An

Cf. František JIRÁNEK et al., Otázky psychologie učení, Praha: SPN, 1970, p. 72.

Cf. Jiří ČERNÝ, Fotbal je hra (pokus o fenomenologii hry), Praha: Československý spisovatel, 1968, p. 11.

Cf. Jan HENDL, Kvalitativní výzkum: Základní metody a aplikace, Praha: Portál, 2005. 
exception was the situations where you had to go shopping or just for a walk with the children. I had to adapt to the regulations that were currently in force. One 'fought' a bit with one's opinion on this current situation and, at the same time, adapted to it. Were it not for the media 'hype' which was around this disease, I might not have even known that something was going on. But because it was talked about and written everywhere, I also lap up daily news and statistics over time. But if someone keeps telling you about the same thing over and over, you will become immune to it over time. You get used to it and it becomes annoying. You get used to it and start behaving accordingly. ${ }^{7}$ Students with this type of attitude express themselves rather conventionally. They said that this phenomenon is here and will be, it gave something and took something, and so it is. The most common message is that life goes on. They hope that everything will be like before.

As for the exam period, I hope we will not have to pass the exams through MS Teams. If so, we will have to do it. We cannot do anything about it. I am already looking forward to overcoming this period. Everything will be the same. We will go to school and to work, we will visit our acquaintances without fear and go to events with friends, and many other things which we used to do and which we miss now. ${ }^{8}$

It is not yet known how long the school closure regulation will last. Entertaining children for a long time is not easy, both small and older ones. Although these regulations are unpleasant and restrictive, I am also trying to find the positives. We will have to learn to live and function as before. And because life is like a mosaic of little joys, I enjoy time with my daughters. We cook and bake sweet things for my husband, we learn, we read, we watch movies together. Life goes on...9

In the case of some students, there are formal clichés and the attempts to stay on top of things and to include conventional humour.

Another finding today may be wearing masks. A year ago, no one would have thought that it would become part of ordinary fashion today and if you do not have it you are kind of special to people. It is a special time, but the main thing is to maintain common sense at this time:-). ${ }^{10}$

If we interpret these statements in terms of content and form, then we will not receive unifying codes. The stressful situation is reflected in the ability of a particular person to somehow face it, i.e., to approach it. For this group of students, it turns out that the situation does not affect them for the various reasons described above. It does not significantly affect the dynamics of their personal involvement.

\section{Frustration, Helplessness, Negation, Cynicism}

In the next group, the attitude code is a certain emotional interest which is experienced through active negativity. In this respect, it brings frustration, actively expressed disinterest - poisoning, the desire for a radical solution, and, at the same time, the awareness of powerlessness.

This whole corona-virus annoys me so much that I do not even know what to add anymore. I turn on the TV, and there it is. I open the newspaper, it is here again. I turn on social networks, it is there again. I am afraid to go to the fridge and the toilet, as it might jump on me there. That would be the end. I really wonder what else will come in 2020. Wheelbarrows could start falling from the sky, right? No, wait, five thousand crown bills would be better. Then life would be beautiful. Oh, it would

Sample from the essay of a student in the $1^{\text {st }}$ year of the bachelor's programme Leisure Education, distance form.

Sample from the essay of a student in the $1^{\text {st }}$ year of the bachelor's programme Leisure Education, on-site form.

Sample from the essay of a student in the $1^{\text {st }}$ year of the bachelor's programme Leisure Education, distance form.

0 Sample from the essay of a student in the $3^{\text {rd }}$ year of the bachelor's programme Leisure Education, distance form. 
not be that way probably, because people would kill each other. So I really do not know what to say. ${ }^{11}$ Based on the emotional attitude set in this way, it is understandable that one would like to join a more radical attitude towards others. However, a kind of helplessness is still dominant. I believe that this type of attitude is very emotionally demanding for such people.

Personally, measures as such are irritating for me, just like for almost everyone. I am trying to follow them as I am trying to be considerate of others. That is the only reason. I am not saying that I never break them, no one can probably say that. As long as I can and as long as I am out of the circle of my friends (those who do not have covid), among strangers, I follow the rules. I cannot know if the shopping assistant in the store has a health problem. If she does and she catches Covid, it would be a death sentence for her. My opinion is that strict regulations, such as a ban on going out or gatherings, had to be introduced by the government because of the irresponsible minority. Now everyone pays for it. It is the same principle as when in a factory, where all the production was done on time despite the fact that someone went to smoke or rest for a while during working hours, there are a few new people who just will not do anything during the whole working time. What can management do then? Well, they can put cameras on that hall to force them to do it. But then everyone pays for the behaviour of these few individuals. Nowadays, unfortunately, it is no longer possible to beat up those few individuals without risking a much larger penalty, although I think that would be the most effective step. ${ }^{12}$

The internal tension of the student is very aptly described, as she chose, as a form of statement, a kind of concise commented statements, slogans, questions, shouts. At the level of attitude, there is a certain cynicism which is probably a defence against frustration from the unhappy emotional mood and the overall societal mood.

Yes, measures may be necessary but to make fun of people every week in a different way? Now you can, now you cannot after 21:00 again? Does anyone else see how beautifully those powerful manipulate people? How does everyone listen? And who knows, it might get worse. This topic can be discussed for a long time, and, at the same time, it makes me so angry to talk about it. Talk about the situation we are in. It is a terrible situation. You cannot go to work, you do not have money..., and paying the rent? You have no savings - bad luck. Do you want at least some money? Take out a loan. You can't even take out a loan? Try to ask relatives. Do they not have money for their own living anymore? Whatever, commit suicide ... nobody talks about it, they do not write about it, nobody sees it... they are blinded... Ha ha, everywhere on the TV news one can hear: 'people help each otherCzechia sews masks'. Let us all come together and let us sew... Yeah ... everyone was so wonderful, kind-hearted, willing at that time. Where is it now? Every day at work, I see how bad people are, and it is getting worse. They are so much more selfish. It is just pure anger. Yes, maybe someone sees it differently... meets only positive people... I am probably not lucky. People complain, insults go from left to right. I can be the nicest, but it will not help. Day by day, it is getting worse. Day by day I see more and more anger. And another topic... money to buy masks for the retired? In a slight irony-> Why should we give them to single mothers? They can manage. After all, milk and nappies, clothes for only a few months for babies cost just a few crowns, don't they? You know... I do not even know which decision is right and which is meaningless. There are so many of them that you really get lost in it quickly. I do not like this period. The world has gone mad. ${ }^{13}$

The following example shows the entire text which is dominated by brevity, highlighted non-compliance with spellings, contempt.

11 Sample from the essay of a student in the $1^{\text {st }}$ year of the bachelor's programme Leisure Education, on-site form.

12 Sample from the essay of a student in the $3^{\text {rd }}$ year of the bachelor' programme Leisure Education, distance form.

13 Sample from the essay of a student in the $3^{\text {rd }}$ year of the bachelor's programme Leisure Education, on-site form. 
I do not think anything special. Maybe I just miss going out at the weekend. I cannot go anywhere with friends, dance, and release all the accumulated stress from the whole week. I cannot sit down for coffee during the week and talk. I miss this a lot because I am such a lounger. But a few weeks ago, something upset me. It was not about me, it was about my friend who had had a headache for 3 months. He was tested and he was negative and he even had antibodies. But even after submitting all the papers, she sent him for tests anyway and did not deal with it anymore. It made me very upset. After all, other diseases have not disappeared, they are still here, they are all around us. There is a flu, sore throat, chicken pox, cancer, and so on... Just because it is not discussed does not mean it is gone. And corona-virus is not the centre of the universe. ${ }^{14}$

What is most appropriate for this attitude group, the attitude code? Emotional activity can be felt from the expression. Individuals do not find satisfactory answers to the questions posed by the crisis. They express their worries, frustration, dissatisfaction, anger.

\section{Anxiety and Worries}

Statements about anxiety and worries are often very strong. The basic code is a certain defensive attitude. Something is going on, we do not have it under control, and we are worried about how it will all turn out. Even if we try to stay calm, doubts come into one's mind. Due to the lack of pedagogical practice and less life experience, younger students focus on themselves and their problems regarding studies more often. There are often statements about experiencing one's own inability to organise time, inability to concentrate, and the need for external motivation.

How has this gloomy covid time affected me? I probably feel the biggest loss in the area of my studies. I am a person who does not have a strong will and patience which is quite a minus when studying from home. Self-study is a punishment for me, I cannot say to myself: 'Now I am going to study this and this..., I need a fixed schedule and regular daily studies at school. I need to listen to lectures live, not via my laptop. I can sit or lie everywhere with it, even in my bed. And so, unfortunately, I take it to bed very often. Then I turn on the lecture and, after a while, I lose my attention. It is not easy at all. ${ }^{15}$

In the following statement, the student describes the difficult situation in the household and the need for a kind of mental hygiene or even the possibility of authorial essays as a therapy.

The Covid situation makes me depressed. I mean it affects me mentally a lot, as I am locked up at home for almost 24 hours with my sneering grandfather and my thoughts. I was already so desperate and unhappy with my studies that I thought I would quit. There were so many things I did not manage to do, and that made me very stressed.... ... Maybe it would help me to find a quiet place with no people, and I could shout out all my worries and think about everything that has happened to me in the last few months. Or it is enough to get rid of it through writing, like right now. This clears my mind a little, and I do not have so many of those serious thoughts. ${ }^{16}$

Older students studying in the distance form worry about relationships in a broader social framework. Jiránek's thesis confirms this fact when saying (in several points) that relationships really exist, the individual reveals them by his activity, this activity develops from material activity into thought activity in connection with the development of abstraction, that is, the ability to take positions on the world which are conditioned more and more socially. In the following example, this relationship framework is very well illustrated by worries about the fate of the individual being

14 Essay of a student in the $3^{\text {rd }}$ year of the bachelor's programme Leisure Education (full text), on-site form.

15 Sample from the essay of a student in the $1^{\text {st }}$ year of the bachelor's programme Leisure Education, on-site form.

16 Sample from the essay of a student in the $1^{\text {st }}$ year of the bachelor's programme Leisure Education, on-site form. 
brought up. It is also an illustration of a very significant pedagogical commitment and, at the same time, a real ability to ask about the broader context of the (non)sense of pedagogical work.

To sum it up: I try to catch up with the teaching plan, I look for things, I answer questions from children and parents, I prepare lessons, I solve mathematics and physics exercises, I paint a blind map, I tutor. I work with children who, in the eighth grade, cannot write a Czech sentence correctly. I am not talking about creating it, I am talking just about writing it. I deal with children with special educational needs or on the border of mental disability. I deal with children who are supported by their parents in inactivity. It is a lot of very hard work with a lousy effect even under 'normal circumstances'. In the covid era, I wonder how much longer one can survive. One of the tasks of a teaching assistant is to support and expand the social skills of your mentee. Distance learning totally broke this task. I am afraid that when we get back to school, ' $m y$ ' children will be in a much worse condition than when I started with them three years ago. I saw them grow. I knew exactly what they could do, what they could be. I loved all of them. In those few years, we got used to each other, and we knew what to expect from each other. But now I have no idea what kind of children I will return to. ${ }^{17}$

Another example is from an essay that obviously worked as auto-therapy. I believe that this is not only a methodological, but mainly an ethical challenge. The student believed that she could open up, share her suffering. She knows that the answers do not fall into the 'machine' that evaluates them objectively. She receives feedback on her statement. She looks for an authentic expression. We cannot receive such deep messages with the help of a quantitative methodology.

Now I am wondering if I should include the biggest hurt here. The one that hit me the most during this period. My grandmother died in May. She had been sick, but none of us had expected that so soon. We had not even thought about it. The last few weeks before her passing away it had got really serious. Do you know what is the worst thing about all this? That due to corona, I could not even say goodbye to her. I curse this bad time every day and blame myself for not visiting her at that time. It had been bad and there were restrictions, but I should have gone there and said goodbye. None of us will ever forget this year. Were it not for my family, with whom I am every day now, it would be really hard to manage all this mentally. I still pray for the end of this, for things to be as before and alright. ${ }^{18}$ If we try to interpret these statements in terms of content and form, then we will not receive unifying codes again. In this case, however, the stressful situation significantly affects the personality structures. Individuals feel very strong pressure and some responsibility for the effects of the situation on themselves, sometimes others. However, they are really defensive when expressing their attitudes, there is even some helplessness. And that increases their sense of anxiety and fear.

\section{Stop, Challenge}

In order to illustrate this attitude group well, I will give an example that corresponds, in terms of content, to the example of the essay in the previous chapter. The author also struggles with the loss of a loved one, even her own child. However, she finds liberation in a specific activity - meaningful work. This activity leads her out of despair, and thus her attitude changes.

My son passed away and I felt a deep sorrow and the whole country mourned with me... My work and my school literally saved me. The fact that I could do such a worthy and meaningful job every day, at least for a little while, was like a balm for my soul pain. I sewed masks. Really, I am not joking.

17 Sample from the essay of a student in the $2^{\text {nd }}$ year of the bachelor's programme Leisure Education, distance form.

18 Sample from the essay of a student in the $1^{\text {st }}$ year of the bachelor's programme Leisure Education, distance form. 
Our school turned into one perfectly functioning and cooperative little factory. Something that could have saved our lives. And so we looked for fabrics, cut, and ironed. Finally, we sewed such beautiful masks which our director was giving to all who needed them.... So how did the epidemic change and affect my profession and my life? I think it restricted me in moving, but I also got something in return. I was given time, time to stop, time to think, and last but not least, time to get to know my own self. ${ }^{19}$ The following sample from the essay shows how the student actively, purposefully, and consciously changes her attitude. She does not take the situation passively, she does not feel socially determined. She realises that there is a lot of room for change in her own approach. In this respect, she is probably trying to implement Frankl's thesis which says that we cannot change social circumstances, but we can change our attitude to them..$^{20}$ It is also very interesting to notice a certain internal dialogue that helps her to change this attitude.

Originally, I planned to talk a lot about my suffering, I wanted to cry here. But I think we all internally fight with ourselves. We want to be able to live with ourselves at least. We each have some worries, we feel blue sometimes. And it is okay at the moment. Therefore, I might take it from a completely different perspective. I am thankful for being healthy. And no one in the family has been particularly affected with covid. I am thankful for being able to spend more time with my family. Otherwise, we would not have time to make coffee, sit down at the table together, play dobble, or just read a book. I am thankful for having a boyfriend with whom I can spend time. Because even though it is nice to spend time with family, each of us knows what cabin fever is. ${ }^{21}$

If we should describe, in any way, the difference in attitudes between the first (more formal) attitude group and this third group, then we can characterise it using the message of the last lines of the example. The author expresses some hope for a change in human behaviour which will lead to responsibility. He believes that covid is a challenge for us to make this change, and he wants to accept the challenge.

Economists quantify the state's debt and the huge financial consequences, and, in fact, the whole of society adds up the losses. I look forward to being able to fully practice my teaching profession again. However, nobody knows under what conditions we will be allowed to teach. I think the corona-virus will remain part of our society. We will have to adapt and live by its side. Many people have already realised this. Unfortunately, some have stopped looking left or right, and they are heading forward. In the same way as they did before Covid-19 and its addition to dictionaries. They are forgetting this message of nature to humanity. But I do not want to go back. We have new challenges, opportunities. These can be the spice of our lives and professions. ${ }^{22}$

In terms of content, these statements also apply to study challenges. Despite internal uncertainty and doubt, however, the active attitude prevails.

Sometimes, in the everyday hustle and bustle, stress, tension, a lot of curriculum, I would like to run away somewhere. I say to myself: 'Why? Do I need it?' But then I stop and assure myself that it actually makes sense. After all, education is so much needed today and the idea that it will help me to get my dream job certainly makes sense. And among other things, it also has its bright moments. Studying allows you to meet new people who, in my experience, can be good partners in life. From my point of view, everyone should have dreams, or goals, that he would like to achieve. One should know one's life path, and that is the meaning of life. So my goal is to study successfully... ${ }^{23}$

19 Sample from the essay of a student in the $1^{\text {st }}$ year of the bachelor's programme Leisure Education, distance form.

20 Cf. Frankl, Vuile...., p. 109.

21 Sample from the essay of a student in the $3^{\text {rd }}$ year of the bachelor's programme Leisure Education, distance form.

22 Sample from the essay of a student in the $2^{\text {nd }}$ year of the bachelor's programme Leisure Education, distance form.

23 Sample from the essay of a student in the $1^{\text {st }}$ year of the bachelor's programme Leisure Education, distance form. 
There are also testimonies of students who have already suffered through the disease and somehow had to react. This example outlines a change in attitude due to this illness. The author describes a kind of relaxation, a better mood. Although he has respect for the disease, his defensive attitude is weakened.

After overcoming the disease, I am generally more relaxed and in a better mood. Before, I was afraid that I would get the disease and I did not know what the course might be. So I respect the disease, I follow all the regulations, I do not meet my parents, grandparents, or anyone else in the family. However, I manage my fear far better than at the beginning... and I still do not read or watch the news on $T V . .{ }^{24}$

\section{Performance Provocation}

Initially, it seemed that the following attitude code could be purely specific with regard to the student's profession. However, then the idea prevailed that it might be the other way around. A certain profession attracts people with a certain attitude towards the world. Although there are only three statements in this attitude group, it is good to see this performance attitude as more general. In addition to a soldier and a policeman, a policewoman is also represented. In terms of attitude, these people are very motivated by the unexpected situation, they discover new energy. They are fortunate enough to have a profession which was the right choice for them professionally and humanly and to be able to help others.

In the first example, this is an attitude that is essentially accelerated by the crisis. The student is aware of the value of his job in the army. It even refers to essays that have already been submitted. In his considerations, he clarifies his almost passionate idea of the possibilities of further education. And he also refers to broader socially conditioned behaviour in terms of his function.

My profession is quite specific at the moment. If I present it in a figurative way, we practice, fight, or wait for a catastrophe..... During this work, one actually realises what one is studying. Thanks to my studies, I am slowly (but surely) getting into the issue. I found out that working in the armed forces, specifically in the military, is closely linked to pedagogy and psychology. Given that I have been in the command corps for a few years now, I have to agree with what is said 'a good commander is a teacher and a psychologist at the same time'... In the first essay, I wrote about my future intentions. After graduating, I wanted to continue my studies so that I could later educate children in sports in basic school. I might reconsider my thinking a bit, because I would like to educate the command corps in the ACR. I am giving myself a big task probably, because no one in the army has yet come up with the idea of educating the lowest command corps. These commanders have no pedagogical education and some are not even empathetic. This is sometimes very annoying. Paradoxically, their main task is to teach their subordinates new skills and pass on their experience. Without these basics, they can never do it right. This would sum up my thinking. Now it is slightly challenging to combine all aspects together. These are work (helping the population of the Czech Republic), family, and studies. But I will not give up, because the team of professors and classmates is excellent. At the same time, my motivation and the idea of developing the command corps as successful teachers drives me forwards... ${ }^{25}$

To illustrate and support this attitude, we can use the essay or the self-reflection of a woman who serves in the police. It shows, in good terms, the value of doing a specific job which is needed,

24 Sample from the essay of a student in the $3^{\text {rd }}$ year of the bachelor's programme Leisure Education, distance form.

25 Sample from the essay of a student in the $1^{\text {st }}$ year of the bachelor's programme Leisure Education, distance form. 
helping, and is becoming a real mission.

I work as a police officer of the Czech Republic in the district department. We are currently divided into groups $A$ and $B$, so that we do not meet each other. We are a small department, and there are currently 11 of us. Our department is really very small, we call it the 'family-type department'. Despite the fact that we all try to wear masks and disinfect everything properly, covid has affected us as well. In such small numbers, we find it difficult to put together services, and now, with covid, it is even worse. As there are really very few of us, we have a lack of staff, and we often have to work overtime. These hours are not counted. We work 12, 24, and 35 hours. Sometimes it is really very difficult. I am glad that despite the atmosphere in covid times, we are all trying to help each other... Some have reevaluated their lives and started living differently, somehow better and at ease. Suddenly they have time to revise their lives. Some do not feel any change and are looking forward to returning back to the 'old ways'. Is it possible? When this is over, will life be the same? And will it ever go away? Be that as it may, I hope it is like in this quote: 'Everything bad is good for something.' I hope that some kind of restart will come, that there will be a new beginning. Before and after covid. I wish you all a happy and loving journey. Thanks to this experience, I realised that I am grateful for my work. Although it is sometimes very demanding and stressful, especially for a woman, and sometimes I would like to do something completely different, I am glad that I have a job. We will see. I want to do the job I was born for. Now I have it and I can be useful. I think my mission is to help people. ${ }^{26}$

This statement opens up space for essays that have a truly deeper, ethical dimension.

\section{Deep Accepting Essays}

The following essay expresses something that could be called a certain art of understanding. The student actively works to make sure that her understanding (considering the client and herself) takes the right direction. She wants to find the meaning in the area of activity and self-acceptance. Despite the fact that the world still revolves around covid, our world is full of other worries that we have to deal with. It is not an easy situation, but I have fighters in my family who have to win over those health problems. I firmly believe that they will win. One small victory happened in my profession. Due to complications regarding the practice, it was possible to work individually with a lady in a wheelchair who has spinal muscular atrophy. Sometimes it is not a simple practice, but somehow, internally, this work fulfils me a lot. Maybe it is because the client can express gratitude and joy so beautifully. I would never guess that I could really find myself in such a job. People admire me, especially my loved ones who appreciate that I started with such a practice. I know it has taken me a step further in my career... ... This has influenced my student life as well, especially writing authorial texts. I dare say that perhaps everyone noticed it during our favourite reading. In the last verses, I slightly implied the pain that is relevant in my life. Each time, for my inner peace, I had to make the text easier. I did it not only for others who have enough of their worries, but mainly for myself. In practice, I realised that in our hectic world, we deal with a lot of banalities. She, my client, opened my eyes. She takes it easy, more than an ordinary person. It is this way, even though she experiences suffering every day. ${ }^{27}$

In the following text, the experience with mental illness has a relatively paradoxical effect. The author perceives this experience as positive, as something that prepared him for today's situation. The text is also dominated by an interest in the psychotherapeutic approach.

26 Sample from the essay of a student in the $2^{\text {nd }}$ year of the bachelor's programme Leisure Education, distance form.

27 Sample from the essay of a student in the $3^{\text {rd }}$ year of the bachelor's programme Leisure Education, on-site form. 
The corona virus pandemic has certainly brought many changes. It has brought an opportunity to think about oneself as well. One can think about the way of living one's life and about preferred values. Everyone should ask oneself the question: Am I happy? Suddenly we have more time. We can reflect upon ourselves. It can be an opportunity for a cleansing catharsis leading to our own self-reflection. 'Many people hate Sunday because they have time to think about their life and lifestyle', says Dalibor Špok, a psychotherapist. It is a test of interpersonal relationships. Due to current measures, people are forced to spend more time at home. And if cohabitation is not ideal, it can make the situation worse, because there are not many opportunities to escape. Another consequence is the home office, i.e., working from home, which is often used. People talk a lot about modern technologies that help to replace the lack of personal contact (a home office, distance learning, or just regular calls). As Dalibor Špok states, distance psychotherapy is a new experience for him as well. I agree with him that a lot of people cannot be just with themselves. They are afraid to admit the problem. They suspect that something is wrong, and that they should change it. This requires effort and sacrifice, patience and time. It is said that the crisis is a chance for change. Every cloud has a silver lining. Perhaps I have a gift to see something good in bad situations and make it useful somehow. In any case, the current situation will make everyone realise that nothing is a matter of course. One needs to appreciate seemingly ordinary things, such as the opportunity to sit with someone and have a coffee. I am lucky enough to have a job that is intended for those who would not have a chance otherwise. Thanks to that, I know what a home office is. And today this fact is becoming more important. People experience more anxiety, depression, and loneliness, similar to those with mental health problems. Since I have known this for many years, I am ready for it. I know what to expect and what to do. It will not surprise me. So these are the positives of the time we are currently experiencing, at least for me.. $.28^{28}$

\section{Distance}

A total of seven essays with their attitude message were somehow difficult to classify, and could not be included among the more general codes. They are either unaffected by any emotion or they deny the problem. Some completed the task only. With their attitude, they distance themselves from the problem, from the assignment, from social events.

My opinion is that this is one big global farce, and our government is the worst. ${ }^{29}$

\section{Summary of Data}

As announced at the beginning of the study, the basic research question was to find out the thought process of individuals which takes place due to the broader social context (in terms of value or ethics). We wanted to know what kind of attitude students have to the new situation. Based on this consideration and qualitative analysis of the submitted works, it can be concluded that students have seven attitude types (codes), which were described above, for the corona-virus crisis. In terms of quantitative ratios, a total of 182 essays (statements) were distributed as follows:

1. 63 respondents, i.e., $35 \%$, express themselves within the attitude code 'It is just like that'.

2. 15 respondents, i.e., $8 \%$, express themselves within the attitude code 'Frustration, helplessness,

28 Sample from the essay of a student in the $1^{\text {st }}$ year of the bachelor's programme Leisure Education, distance form.

29 Sample from the essay of a student in the $1^{\text {st }}$ year of the bachelor's programme Leisure Education, distance form. 
negation, cynicism'

3. 41 respondents, i.e., $22 \%$, express themselves within the attitude code 'Anxiety and worries'.

4. 37 respondents, i.e., 20\%, express themselves within the attitude code 'Stop, challenge'.

5. 3 respondents, i.e., $2 \%$, express themselves within the attitude code 'Performance provocation'.

6. 16 respondents, i.e., $9 \%$, express themselves within the attitude code 'Deep accepting essays'.

7. 7 respondents, i.e., $4 \%$, express themselves within the attitude code 'Distance'.

\section{Discussion and conclusion}

The use of a qualitative methodology gives a more authentic message about the attitudes of specific students. The resulting scheme is created from the bottom - the individual attitude categories emerged from the texts themselves. The process was based on the interpretation of the phenomenon of the corona-virus crisis. ${ }^{30}$ Respondents do not have to be classified and adapted to the categories prepared by the researcher in the structure of the questionnaire. They created the categorisation themselves, with their statements. The research thus outlines a more ethical view of the participant, who is a partner in terms of participation. It is more like research 'with people' rather than research 'about people.' The latter is primarily about obtaining data. Given that the first comparable data will be coming at the time of publication of this issue of the journal, we wonder whether our fellow researchers have taken into account the attitude codes of the research participants when collecting the data. In this respect, space is opened for future comparative studies and methodological assessments of individual procedures.

Considering the distribution of attitude codes in the researched sample of students of the bachelor's programme Leisure Pedagogy, we can start from three directions of personality dynamics. Codes 1 and 7 represent an indistinct or formal attitude. Codes 2 and 3 represent a certain degree of defensive attitude which goes from fear to frustration. Codes 4, 5, and 6 point to a certain scale of one's own active approach to a problematic situation (from stopping in time to activity or deeper thinking based on an unexpected situation). In this respect, the approximate percentage distribution of these groups is about 40:30:30. The initial idea leads to the fact that $40 \%$ of students with an indistinct or formal attitude create a relatively high number among the students of helping professions. On the other hand, there are $60 \%$ of students who, in some way, reflect upon their attitude more strongly (either defensively or actively). These numbers can be a good input not only for discussions about the social impact of the corona-virus crisis, but they can help define the desired personality and attitudes of students and workers in the helping professions as well.

\section{Contact}

\section{Assoc. Prof. MgA. Stanislav Suda}

University of South Bohemia in České Budějovice

Faculty of Theology

Department of Pedagogy

Kněžská 8, 37001 České Budějovice

suda@tf.jcu.cz 